\title{
Combined Stimulation with Interleukin-18 and Interleukin-12 Potently Induces Interleukin-8 Production by Natural Killer Cells
}

\author{
Sophie M. Poznanski ${ }^{\mathrm{a}}$ Amanda J. Lee ${ }^{\mathrm{a}}$ Tina Nham $^{\mathrm{a}}$ Evan Lusty ${ }^{\mathrm{a}}$ \\ Margaret J. Larchéb Dean A. Lee ${ }^{c}$ Ali A. Ashkar ${ }^{a}$

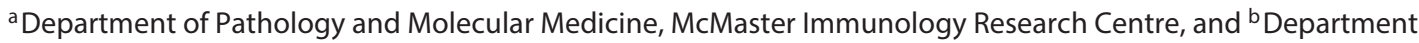 \\ of Medicine, McMaster University, Hamilton, ON, Canada; ' Cellular Therapy and Cancer Immunology Program, \\ Department of Hematology/Oncology and BMT, Nationwide Children's Hospital, The Ohio State University \\ Comprehensive Cancer Center, Columbus, OH, USA
}

\section{Keywords}

Natural killer cells · Immunotherapy · Innate immunity · Cytokines

\begin{abstract}
The combination of interleukin (IL)-18 and IL-12 (IL-18+IL-12) potently stimulates natural killer (NK) cells, triggering an innate immune response to infections and cancers. Strategies exploiting the effects of IL-18+IL-12 have shown promise for cancer immunotherapy. However, studies have primarily characterized the NK cell response to IL-18+IL-12 in terms of interferon (IFN)- $\gamma$ production, with little focus on other cytokines produced. IL-8 plays a critical role in activating and recruiting immune cells, but it also has tumor-promoting functions. IL-8 is classically produced by regulatory NK cells; however, cytotoxic NK cells do not typically produce IL-8. In this study, we uncover that stimulation with IL-18+IL-12 induces high levels of IL-8 production by ex vivo expanded and freshly isolated NK cells and NK cells in peripheral blood mononuclear cells. We further report that tumor necrosis factor (TNF)- $a$, produced by NK cells following IL-18+IL-12 stimulation, regulates IL- 8 production. The IL- 8 produced is in turn required for maximal IFN- $\gamma$ and TNF-a production. These
\end{abstract}

\section{KARGER}

(C) 2017 S. Karger AG, Basel

E-Mail karger@karger.com

www.karger.com/jin findings may have important implications for the immune response to infections and cancer immunotherapies. This study broadens our understanding of NK cell function and IL-18+IL-12 synergy by uncovering an unprecedented ability of IL-18+IL-12-activated peripheral blood NK cells to produce elevated levels of IL-8 and identifying the requirement for intermediates induced by IL-18+IL-12 for maximal cytokine production following stimulation.

(c) 2017 S. Karger AG, Basel

\section{Introduction}

Natural killer (NK) cells are innate immune lymphoid cells that play a critical role in the body's early defense against viruses and cancer due to their ability to recognize and lyse virally infected and malignant cells without prior sensitization and initiate adaptive immune responses [1]. Due to these important attributes, much research has focused on further elucidating NK cell responses in order to exploit their antiviral and antitumor functions for antiviral and cancer therapies $[2,3]$. NK cells have a central role in initiating and coordinating the immune response through the secretion of cytokines, i.e., interferon (IFN)- $\gamma$,

Dr. Ali A. Ashkar

Department of Pathology and Molecular Medicine McMaster Immunology Research Centre, McMaster University 1280 Main Street West, MDCL 4015, Hamilton, ON L8S 4L8 (Canada)

E-Mail ashkara@mcmaster.ca 
and interactions with other immune cells [4]. NK cells can be activated in vivo through a balance of activating and inhibitory signals transmitted through membranebound receptors and by cytokines secreted by activated antigen-presenting cells (APC) [4]. Both interleukin (IL)18 and IL-12 are cytokines secreted by APC in response to stimulatory signals $[5,6]$. IL- 18 and IL- 12 both play critical roles in enhancing NK cell activity, IFN- $\gamma$ production, and modulating the immune response. Studies have indicated a critical role for IL-12 in the dendritic cell-mediated activation of NK cells [7]. Furthermore, IFN- $\gamma$ produced as a result of IL-12 activation can reciprocally promote IL-12 secretion by APC, generating an inflammatory positive feedback loop [5]. Similarly, IL-18 secreted by APC has been shown to induce IFN- $\gamma$ production by NK cells and drive the reciprocal activation of APC and NK cells [8]. The critical role for IL-18 in NK cell activity has been established by demonstrating that IL18-deficient mice have impaired NK cell activity and susceptibility to infection [9]. The effects of IL-18 and IL-12 on NK cells are tightly intertwined. Indeed, Chaix et al. [10] demonstrated that IL-18 is required to prime NK cells to produce IFN- $\gamma$ in response to IL-12.

Combined stimulation with IL-18 and IL-12 (IL18+IL-12) has a powerful synergistic effect on NK cell activation and triggers an important immune response to infections [11]. Stimulation with both IL-18 and IL-12 induces greater NK cell degranulation and IFN- $\gamma$ production compared to stimulation with IL-18 or IL-12 alone [12]. Stimulation with the combination of IL-18, IL-15, and IL-12 has also been shown to generate memory-like NK cells which demonstrate enhanced responsiveness upon restimulation [13]. Although there has been much research focused on NK cell IFN- $\gamma$ production resulting from IL-18+IL-12 stimulation, few studies have examined other cytokines produced. One study demonstrated that different combinations of IL-18, IL-15, and IL-12 differentially induced IL-10, macrophage inflammatory protein (MIP)- $1 \alpha$, MIP-1 $\beta$, tumor necrosis factor (TNF)- $\alpha$, and granulocyte macrophage colony-stimulating factor production by NK cells [14]. However, identifying other cytokines highly produced by NK cells in response to IL-18+IL-12 stimulation would help to further elucidate this critical immune response to infection.

Importantly, the potent stimulatory effect of IL$18+\mathrm{IL}-12$ has also been shown to reverse NK cell anergy in the tumor microenvironment [15]. The use of NK cells as an immunotherapeutic agent for treating cancers has emerged due to their natural ability to recognize and eliminate malignant cells. As a result of the potent en- hancement of IL-18+IL-12 on NK cell activity, different immunotherapeutic strategies employing IL-18+IL-12 have garnered much attention for the treatment of cancer. For instance, IL-18+IL-12 administration was shown to reduce the tumor burden in a hepatoma model [16]. In addition, preactivation of NK cells with the combination of IL-18+IL-15+IL-12 has been developed as a method of enhancing NK cell survival and effector function upon adoptive transfer and it was shown to reduce the tumor burden and increase survival in a murine lymphoma model [17]. Recently, IL-18+IL-15+IL-12 preactivated NK cells were shown to induce a clinical response following adoptive transfer to patients with myeloid leukemia [18]. Given the clear potential for treatments employing IL-18+IL-12, it is pertinent to identify and characterize the production of other cytokines highly upregulated by NK cells following IL-18+IL-12 stimulation and assess the implications that such cytokines could have in humans.

IL-8, also termed CXCL8, is a chemokine that was originally characterized as a neutrophil chemoattractant and activating factor [19]. Since its discovery, it has been shown to also induce migration of other immune cells, including T cells, NK cells, and monocytes [20, 21]. The important role of IL-8 in the host response to infection has been outlined by studies showing that absence or inhibition of the IL-8 receptor CXCR2 causes an increased pathogen burden in various infections [22, 23]. In addition to its functions for host defense, it has been well established that IL-8 has multiple tumor-promoting functions, such as tissue remodeling and angiogenesis, and it is implicated in tumor progression [24]. While resting human peripheral blood NK cells do not spontaneously produce IL-8, IL-8 production is characteristic of decidual NK cells [25]. Contrary to the classic antiviral and antitumour roles of NK cells, decidual NK cells are considered immunoregulatory as they play a critical role in tissue remodeling and angiogenesis, functions that are likely to support tumor growth in the context of a tumor environment [25].

In the present study, we further characterize the NK cell response to IL-18+IL-12 by revealing that IL-18+IL-12 stimulation potently induces IL- 8 production by primary human NK cells in multiple contexts. Furthermore, we demonstrate that TNF- $\alpha$, secreted by NK cells in response to IL-18+IL-12 acts as an intermediate to propagate IL-8 production by NK cells. In turn, the IL- 8 produced plays a critical intermediary role in propagating maximal IFN- $\gamma$ and TNF- $\alpha$ production following IL-18+IL-12 stimulation. These findings further our understanding of this im-
512

J Innate Immun 2017;9:511-525

DOI: $10.1159 / 000477172$
Poznanski/Lee/Nham/Lusty/Larché/Lee/ Ashkar 
portant NK cell response and may have profound implications for the immune response to infections as well as cancer immunotherapies that employ IL-18 and IL-12.

\section{Materials and Methods}

\section{Cell Isolation and Expansion}

Peripheral blood mononuclear cells (PBMC) were isolated from whole blood of healthy donors using Lymphoprep (StemCell Technologies, Vancouver, BC, Canada) for gradient density centrifugation. For NK cell isolation, CD56+ cells were isolated from PBMC using an EasySep human CD56 positive selection kit (StemCell Technologies) according to the manufacturer's protocol. For NK cell expansion, NK cells were expanded ex vivo from PBMC using K562-based feeder cells expressing membrane-bound IL-21 (K562-mb-IL-21) for 3 weeks, as previously described [26]. For microarray, expanded NK cell cultures were further purified with EasySep human CD56 positive selection and human CD3 positive selection kits (StemCell Technologies) following the manufacturer's protocol.

\section{Cell Stimulation}

PBMC, expanded NK cells, or isolated CD56+ cells were used for stimulation. Cells $\left(2 \times 10^{5}\right)$ were stimulated for $24 \mathrm{~h}$ with various cytokine combinations. Cytokines and antibodies were used at the following final concentrations: IL-18 (100 ng/L) (MBL, Japan), IL-15 (20 ng/mL), IL-12 (10 ng/mL), IL-2 (100 U/mL) (Peprotech, Burlington, ON, Canada), anti-human IFN- $\gamma(10 \mu \mathrm{g} / \mathrm{mL})(B i o-X-$ Cell, West Lebanon, NH, USA), anti-human TNF- $\alpha(10 \mu \mathrm{g} / \mathrm{mL})$, TNF- $\alpha$ (1,500 pg/mL) (eBioscience, San Diego, CA, USA), IL-8 antibody $(10 \mu \mathrm{g} / \mathrm{mL})$ (R\&D Systems, Minneapolis, MN, USA), etanercept ( 10 or $1 \mu \mathrm{g} / \mathrm{mL}$ ) (Immunex Corp, Thousand Oaks, CA, USA), and IgG1 isotype control $(10 \mu \mathrm{g} / \mathrm{mL})$ (MyBioSource, San Diego, CA, USA). Supernatants were collected at various time points following the beginning of stimulation. Collected supernatants were used to quantify IL-8, IFN- $\gamma$, or TNF- $\alpha$ levels with respective DuoSet ELISA kits (R\&D Systems).

\section{Microarray}

RNA was isolated from purified, expanded NK cells using a Qiagen RNeasy Mini Kit and RNA quality was determined using a General Electric NanoVue and Bioanalyzer (Agilent Technologies, Santa Clara, CA, USA). Samples with a $260 / 280 \mathrm{~nm}$ ratio \pm 0.1 from 2.0 were used for experiments. RNA was quantitated using Quant-iTTM RiboGreen ${ }^{\circledR}$ RNA Assay (Life Technologies, Carlsbad, CA, USA) and normalized. RNA was amplified and cRNA was synthesized using an Illumina ${ }^{\circledR}$ TotalPrepTM RNA Amplification Kit (Life Technologies). Samples were quantitated with RiboGreen (Life Technologies) and normalized. Samples were subsequently tested using the direct hybridization whole-genome expression method and HumanHT-12 v4 Expression BeadChip Kit and scanned using an iScan microarray scanner (Illumina, San Diego, CA, USA). Data was analyzed using GenomeStudio (Illumina) and $R$ commander.

Flow Cytometric Staining

Golgi Stop (BD Biosciences, San Jose, CA, USA) was added to samples $8 \mathrm{~h}$ before the samples were stained. Flow cytometric staining was conducted on NK cells and PBMC following stimulation. Cells were first stained with fixable viability dye (eBioscience) in PBS for 30 min, washed, and then stained with extracellular antibodies in FACS buffer as well as corresponding FMO with isotype controls. Cells were fixed with Cytofix/Cytoperm (BD Biosciences) for $20 \mathrm{~min}$ and then washed and stained for intracellular markers with antibodies in $1 \times$ BD Perm/Wash buffer (BD Biosciences) for $30 \mathrm{~min}$ with isotype controls in corresponding FMO. Data acquisition was conducted on the BD LSRII or the BD LSRFortessa (BD Biosciences). Fifty thousand NK cell events were collected for expanded and freshly isolated NK cells, 30,000 NK cell events were collected for NK cells in PBMC, and 100,000 NK cell events were collected for phenotyping IL-8+ and IL-8NK cells. Data was analyzed using FlowJo software (Tree Star, Ashland, OR, USA).

The following antibodies were used: anti-human CD56-PE CF594, anti-human CD3-APC H7, anti-human NKp46-BV786, anti-human CD69-PE CF594, anti-human CD11b-PE CF594, PE-

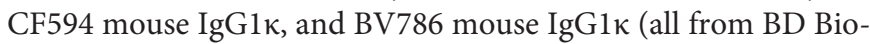
sciences); anti-human CD56-BV421, anti-human CD16-Alexa Fluor 700, anti-human NKG2D-PerCpCy5.5, anti-human NKp44, anti-human NKp30, anti-human CD27-PerCpCy5.5, anti-human CD25-BV785, anti-human CD158b-PE, anti-human CD158e1-

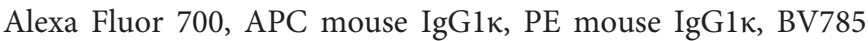

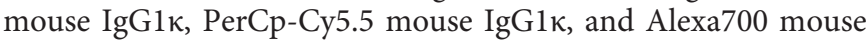
IgG1א (all from BioLegend, San Diego, CA, USA); anti-human IL8-APC (eBioscience); and anti-human NKG2A-PE-Vio770 and REA control PE-Vio770 (both from Miltenyi Biotec, Bergisch Gladbach, Germany).

\section{Statistical Analysis}

Statistical analysis was conducted using GraphPad Prism software (San Diego, CA, USA). Graphs comparing 2 conditions were analyzed via an unpaired $t$ test. Graphs comparing 3 or more conditions were analyzed via one-way ANOVA followed by the Tukey method to correct for multiple comparisons.

\section{Results}

Combined Stimulation with IL-18+IL-12

Synergistically Upregulates IL-8 Production by

ex vivo Expanded NK Cells

Due to the known synergistic effect of IL-18+IL-12 on NK cell activation and IFN- $\gamma$ production, we conducted a microarray on ex vivo expanded NK cells to determine whether the gene expression of other cytokines was highly upregulated following IL-18+IL-12 stimulation (Fig. la, b). Ex vivo expansion of NK cells has been developed as a method of efficiently generating high numbers of NK cells. The adoptive transfer of expanded NK cells is currently undergoing clinical trials for cancer immunotherapy (NCT01904136). Thus, it was pertinent to study the effects of IL-18+IL-12 on ex vivo expanded NK cells. Surprisingly, the microarray results revealed that,

J Innate Immun 2017;9:511-525

IL-18+IL-12 Induces IL-8 Production by

NK Cells

DOI: $10.1159 / 000477172$ 


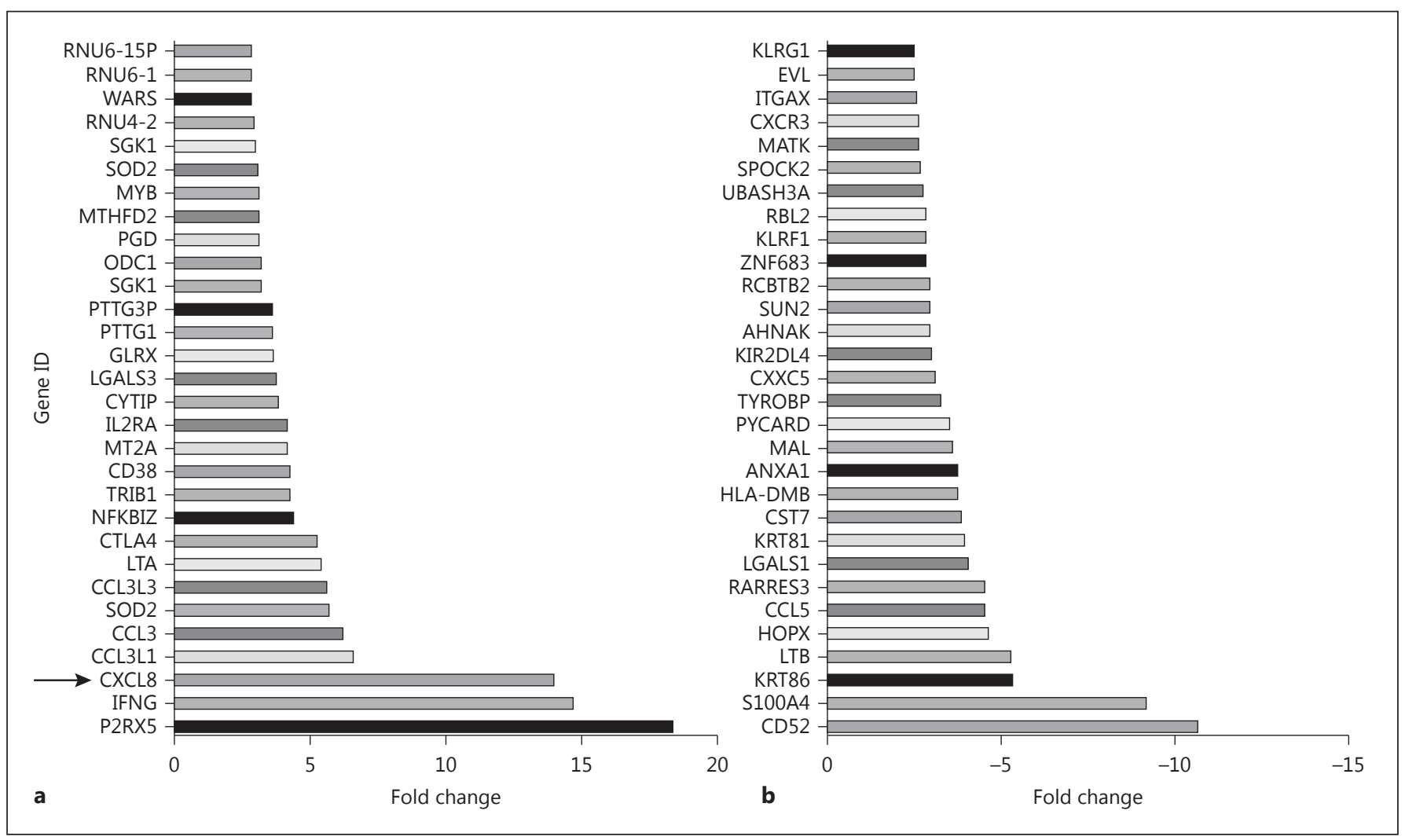

Fig. 1. Combined stimulation with interleukin (IL)-18 and IL-12 (IL-18+IL-12) synergistically upregulates natural killer (NK) cell IL-8 gene expression and protein production. Ex vivo expanded NK cells were stimulated with cytokines or media alone for $24 \mathrm{~h}$ and then washed. Results of the top most up- (a) and downregulated (b) genes with the fold change in gene expression normalized to the unstimulated control $(n=3)$. c Supernatants were collected at $24 \mathrm{~h}$ from which IL-8 levels were quantified via ELISA $(n=3)$. Results were analyzed by one-way ANOVA. ${ }^{* * *} p<0.001$.

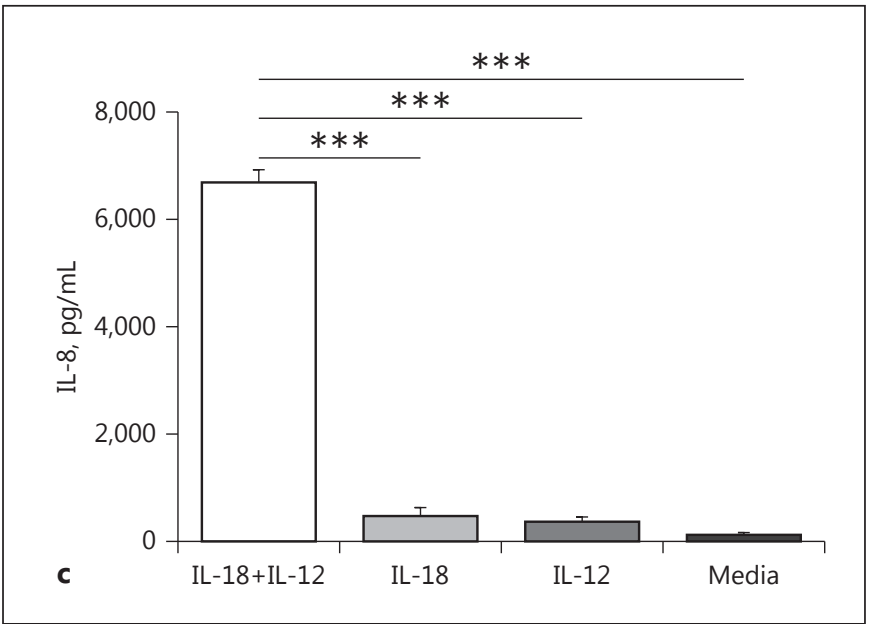

along with IFN- $\gamma$, the IL- 8 gene was among the top most upregulated genes as measured by fold change in gene expression compared to the unstimulated control (Fig. $1 \mathrm{a}, \mathrm{b})$. Given these results, we sought to determine whether the fold change in IL- 8 gene expression translated to high levels of IL-8 protein secretion. Indeed, NK cells stimulated with IL-18+IL-12 produced significantly greater levels of IL-8 protein compared to IL-18, IL-12,

or media alone, demonstrating a strong synergistic effect of IL-18+IL-12 on IL-8 production (Fig. 1c).

We then assessed the purity of the expanded NK cell cultures and visualized the cell type producing IL- 8 in the cultures via flow cytometry to confirm that the IL- 8 was being produced by NK cells. In both IL-18+IL-12 and media-alone conditions, the purity of the NK cell population, defined as CD56+CD3-, was $>95 \%$ (Fig. 2a). Gating 


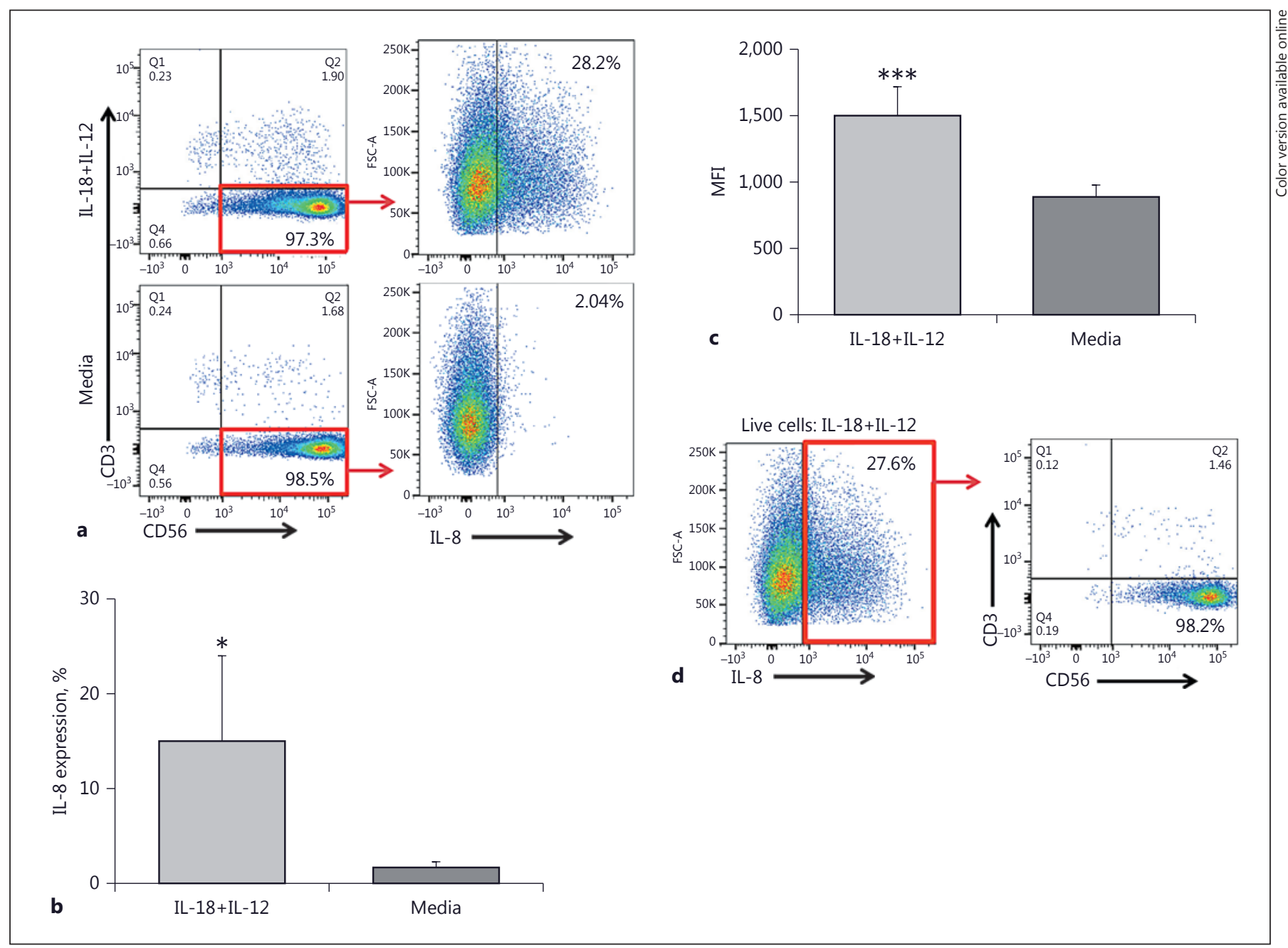

Fig. 2. Interleukin (IL)-8 in natural killer (NK) cell cultures stimulated with IL-18 and IL-12 (IL-18+IL-12) is produced directly by NK cells. Expanded NK cells were stained for IL-8 following $24 \mathrm{~h}$ of stimulation and the NK cell population producing IL- 8 was assessed via flow cytometry. a Representative flow plots of the pro- portion of NK cells producing IL-8. $\mathbf{b}$ The percent of NK cells that expressed IL-8 was quantified $(n=3)$. c Mean fluorescence intensity (MFI) of IL- $8+$ NK cells $(n=3)$. d Representative flow plots of the total cell population producing IL-8. Results were analyzed using an unpaired $t$ test. ${ }^{*} p<0.05,{ }^{* * *} p<0.001$. K, thousand. on this NK cell population, a significantly greater IL-8 expression was observed in IL-18+IL-12-stimulated NK cells as compared to NK cells in media only (Fig. 2a, b). Furthermore, the mean fluorescence intensity (MFI) of the IL-8+ NK cell population stimulated with IL-18+IL-12 was significantly greater than that of unstimulated NK cells (Fig. 2c). To confirm that the absolute levels of IL-8 measured via ELISA were due to NK cell IL- 8 production, the proportion of NK cells in the total live IL- $8+$ cell population was assessed. NK cells accounted for $>95 \%$ of the live cells producing IL-8 (Fig. 2d). Collectively, these results reveal that stimulation with IL-18+IL-12 synergisti- cally induces substantial IL-8 production by expanded NK cells.

\section{IL-18+IL-12-Induced IL-8 Production Extends to both}

Freshly Isolated NK Cells and NK Cells in PBMC

In addition to determining that ex vivo expanded NK cells produce IL-8, it was important to identify whether primary, freshly isolated NK cells produce IL-8 following IL-18+IL-12 stimulation in order to ensure that IL-8 production was not just a phenomenon of the expansion protocol. Freshly isolated NK cells were found to produce striking amounts of IL-8 upon IL-18+IL-12 stimu- 


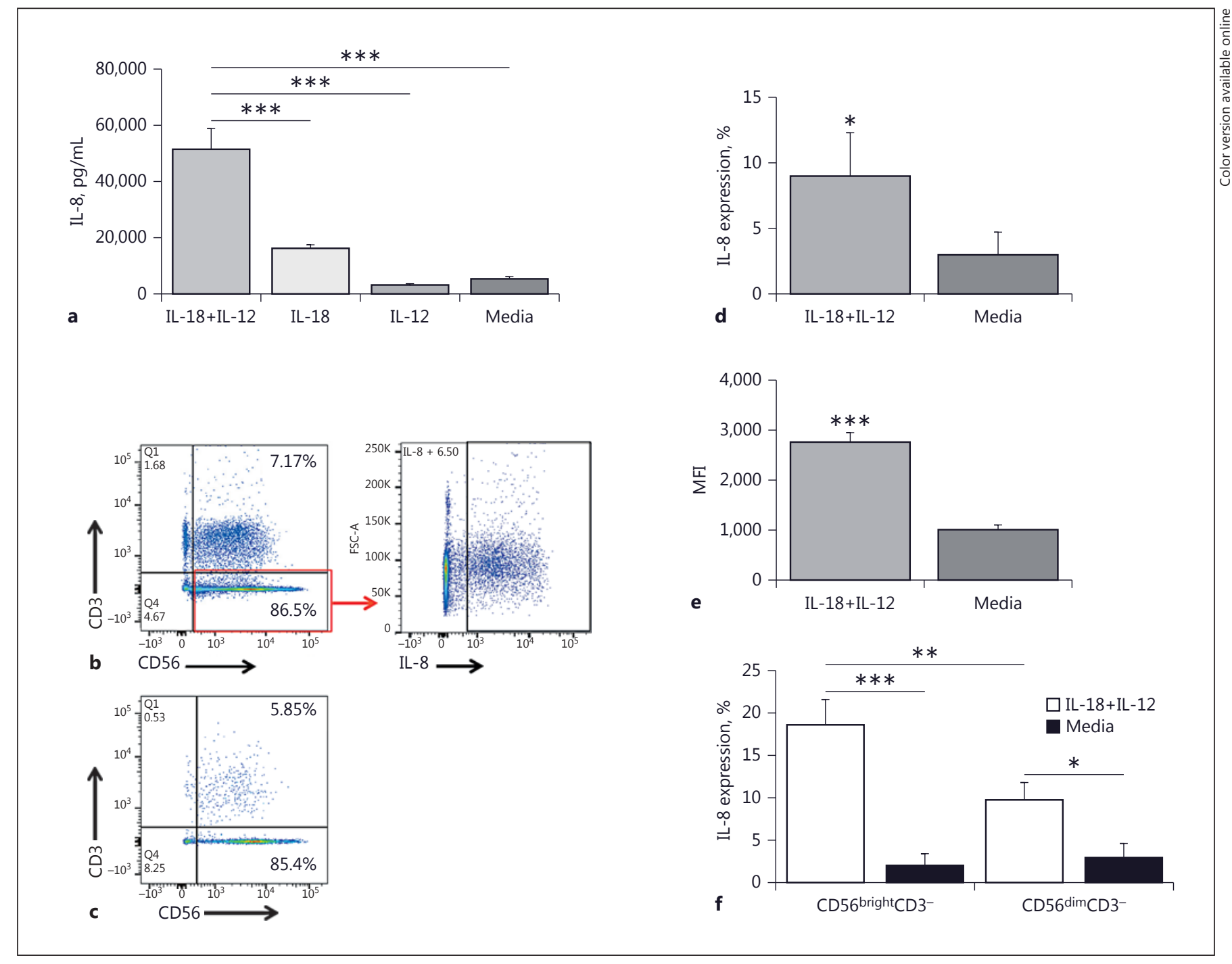

Fig. 3. Freshly isolated primary, unexpanded natural killer (NK) cells produce interleukin (IL)-8 following stimulation with IL-18 and IL-12 (IL-18+IL-12). CD56+ cells were stimulated for $24 \mathrm{~h}$. a Supernatants were collected at $24 \mathrm{~h}$ and used to quantify IL- 8 levels. Results were analyzed via one-way ANOVA. ${ }^{* * *} p<0.001$ $(n=4)$. b Representative flow plot of the live cell population following CD56+ cell isolation and of the IL-8+ shift in the stimulated NK cell population. c Representative flow plot of the subsets

lation and significantly greater amounts than IL-18, IL12, or media alone (Fig. 3a). As shown in Figure 3b, the isolated population consisted of $>90 \%$ CD $56+$ cells, the majority of which were NK cells which exhibited a clear IL-8+ shift following IL-18+IL-12 stimulation. Gating on all live cells that were IL-8+ following IL-18+IL-12 stimulation demonstrated that between 90 and $95 \%$ of cells producing IL-8 were CD56+ (Fig. 3c). In addition, both constituting the live cell IL-8+ population following IL-18+IL-12 stimulation. Percent (d) and mean fluorescence intensity (MFI) (e) of NK cells (CD56+CD3-) expressing IL-8. Results were analyzed using an unpaired $t$ test. ${ }^{*} p<0.05,{ }^{* * *} p=0.0001(n=3)$. f Percent of IL- 8 expression for the CD56 $6^{\text {bright }}$ and CD $56^{\text {dim }}$ NK cell subsets. Results were analyzed via one-way ANOVA. ${ }^{* * *} p<$ $0.0001,{ }^{* *} p<0.01,{ }^{*} p<0.05(n=3) . \mathrm{K}$, thousand.

the percent of freshly isolated NK cells expressing IL-8 and IL-8 MFI were significantly greater in the IL18+IL-12 condition compared to values with media alone (Fig. 3d, e). Since NK cells can be functionally classified based on the level of CD56 expression, with CD$56^{\mathrm{dim}} \mathrm{NK}$ cells being more cytotoxic and CD56 ${ }^{\text {bright }}$ cells considered to be more immunoregulatory with a greater propensity for cytokine production, we further stratified 


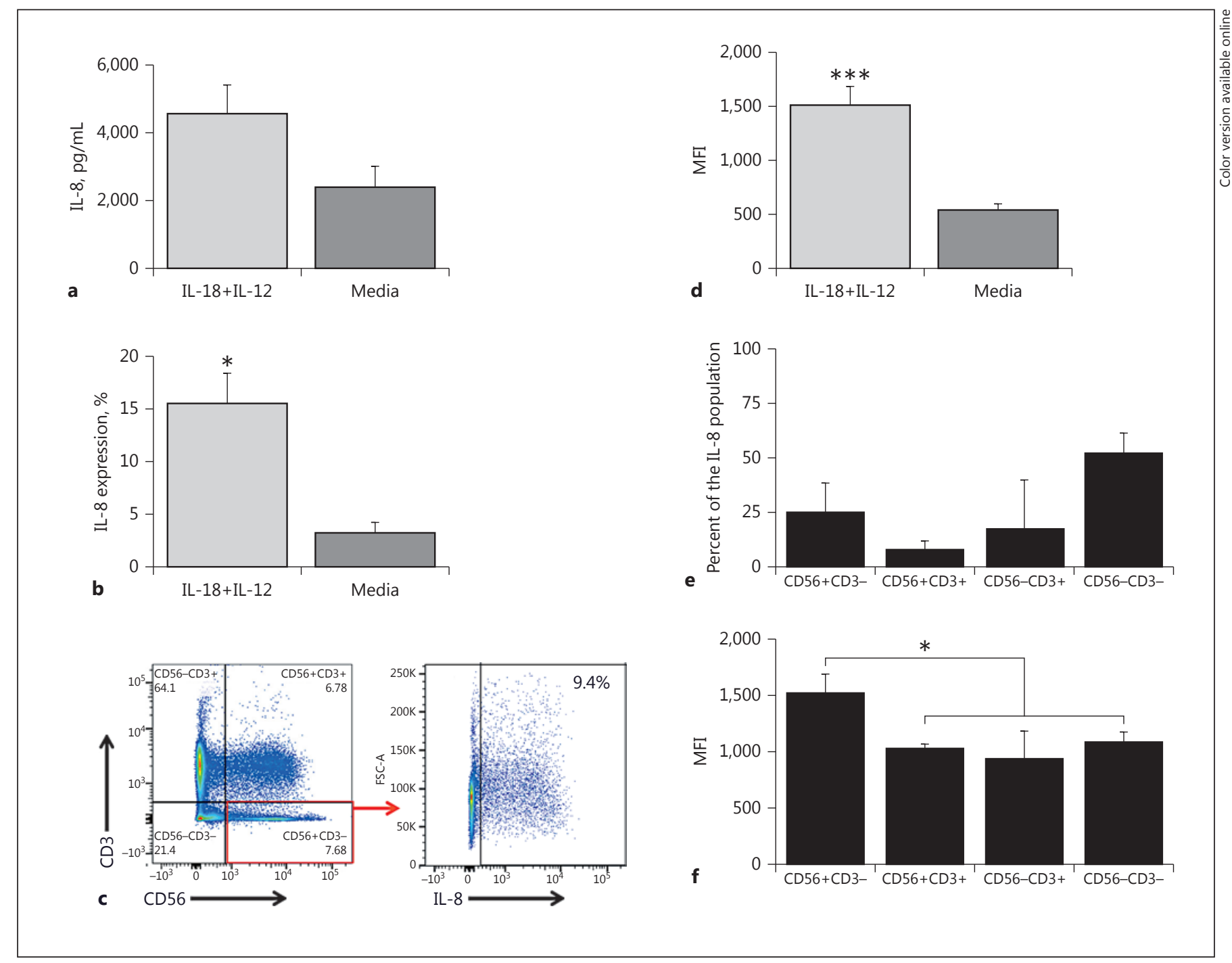

Fig. 4. Natural killer (NK) cells in the context of peripheral blood mononuclear cells (PBMC) produce interleukin (IL)-8 following stimulation with IL-18 and IL-12 (IL-18+IL-12). PBMC were isolated from whole blood and stimulated with IL-18+IL-12 or media alone for $24 \mathrm{~h}$. a PBMC supernatants were collected following stimulation and IL-8 levels were quantified via ELISA. b The proportion of NK cells (CD56+CD3-) producing IL-8 was analyzed following stimulation via flow cytometry. Results were analyzed using an unpaired $t$ test. ${ }^{*} p<0.05(n=3)$. c Representative flow plots of the IL-18+IL-12-stimulated live cell PBMC population and NK cell IL- 8 shift. d MFI of IL-8+ NK cells (CD56+CD3-) producing IL-8. Results were analyzed using an unpaired $t$ test. *** $p<0.001(n=3)$. e Percent of different cell populations constituting the IL- $8+$ PBMC population $(n=3)$. $\mathbf{f}$ Comparison of MFI across IL-8+ populations. Results were analyzed via one-way ANOVA. ${ }^{* *} p<0.01(n=3)$. K, thousand.
NK cells as CD $56^{\text {bright }}$ or CD $56^{\text {dim }}$ and assessed IL- 8 production following IL-18+IL-12 stimulation (Fig. 3f). While following stimulation the CD56 ${ }^{\text {bright }}$ subset had a significantly greater IL-8 expression than the CD56 ${ }^{\text {dim }}$ subset, IL-18+IL-12 stimulation upregulated IL-8 expression by both subsets. Taken together, these results demonstrate that IL-18+IL-12 stimulation induces high

IL-18+IL-12 Induces IL-8 Production by NK Cells levels of IL- 8 production by primary, freshly isolated CD56 $6^{\text {bright }}$ and CD56 ${ }^{\text {dim }}$ NK cells.

With the establishment that both primary expanded and freshly isolated NK cells produce IL-8 following stimulation with IL-18+IL-12, we sought to determine whether this phenomenon also occurred with NK cells in the context of PBMC as this more closely mirrors an in vivo en- 
Fig. 5. Interleukin (IL)-15 and IL-2 each enhance the synergistic effect of IL-18 and IL-12 (IL-18+IL-12) on natural killer (NK) cell IL-8 production. Expanded NK cells were stimulated with cytokines or media alone for $24 \mathrm{~h}$. Supernatants were collected at $24 \mathrm{~h}$ and used to quantify IL-8 levels via ELISA. Results were analyzed by one-way ANOVA. ${ }^{* * *} p<0.0001,{ }^{* *} p<0.01(n=3)$.

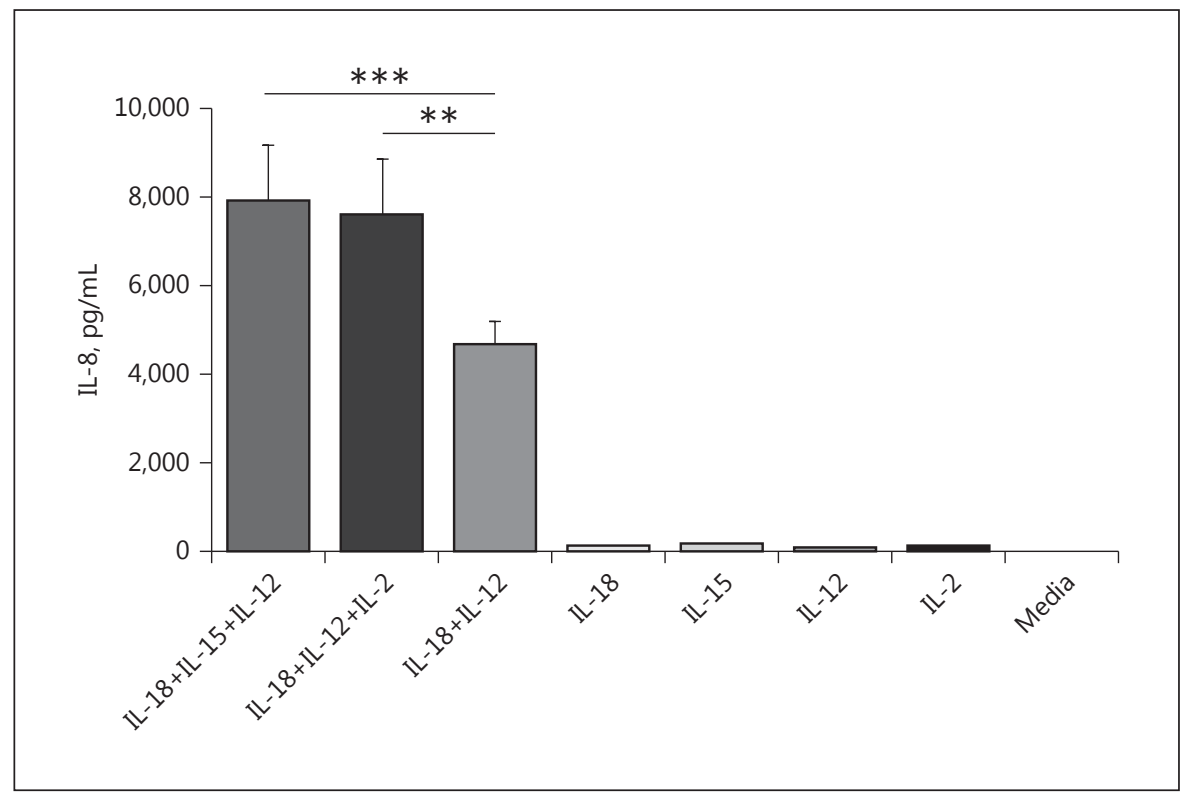

vironment in which NK cells are interacting with other immune cells and receiving supplementary signals. IL18+IL-12 stimulation approximately doubled the amount of IL-8 produced by PBMC (Fig. 4a). Consistent with the results observed with pure NK cells, IL-18+IL-12 stimulation induced a significantly greater percent (Fig. 4b, c) and MFI (Fig. 4d) of NK cells in PBMC expressing IL-8 compared to media alone, demonstrating that this synergistic induction of IL-8 also occurs in the context of PBMC. While other cell types did produce IL-8 following stimulation, NK cells (CD56+CD3-) constituted between 10 and $40 \%$ of IL-8-producing cells despite making up only a small percent of the total PBMC population (Fig. 4e). Small populations of both NKT and T cells also produced IL-8 following stimulation, indicating that the IL-8 response to stimulation may occur across lymphocytes and is not limited to NK cells. However, the MFI of NK cells was the highest observed among the different cell populations (Fig. 4f). Together, these results indicate that while NK cells are not the only cell type in PBMC that produces IL-8 following IL-18+IL-12 stimulation, the IL- 8 produced by NK cells consists of a substantial source of the IL- 8 produced by PBMC following IL-18+IL-12 stimulation.

\section{IL-2 or IL-15 Further Potentiates}

IL-18+IL-12-Induced IL-8 Production by NK Cells

Having established the synergistic effect of IL-18+IL-12 on NK cell IL-8 production, we then explored whether other cytokines could further enhance this synergy. IL-15 and IL-2 are known NK cell activators and survival factors and they have been shown to synergize with IL-18 and IL-12 [27]. Furthermore, IL-18+IL-12 stimulation has been shown to upregulate the expression of a highaffinity IL-2 receptor on NK cells, enhancing the sensitivity of NK cells to IL-2 [28]. Thus, it was pertinent to identify whether stimulation with IL-2 or IL-15 in combination with IL-18+IL-12 further enhanced NK cell IL-8 production. Indeed, the addition of either IL-2 or IL-15 to IL-18+IL-12 stimulation significantly enhanced NK cell IL-8 production as compared to IL-18+IL-12 alone, demonstrating that other cytokines are capable of further synergizing with IL-18+IL-12 to amplify this IL-8 response (Fig. 5).

\section{Following IL-18+IL-12 Stimulation, IL-8+ NK Cells}

Are Phenotypically Similar to IL-8- NK Cells

Since the results in Figure $2 \mathrm{~b}$ demonstrated that only a subset of NK cells are positive for IL-8 following stimulation with IL-18+IL-12, we conducted a phenotypic analysis of the expanded NK cells following IL-18+IL-12 stimulation to determine whether the population of NK cells that produced IL-8 was phenotypically distinct from the NK cells that did not produce IL-8. We assessed phenotype via flow cytometric staining for various NK cell activation markers (Fig. 6a), inhibitory markers (Fig. 6b), and maturation markers (Fig. 6c) and compared the expression of these markers between the IL-8+ and IL-8NK cell populations. Representative histograms for each
518

J Innate Immun 2017;9:511-525

DOI: $10.1159 / 000477172$
Poznanski/Lee/Nham/Lusty/Larché/Lee/ Ashkar 


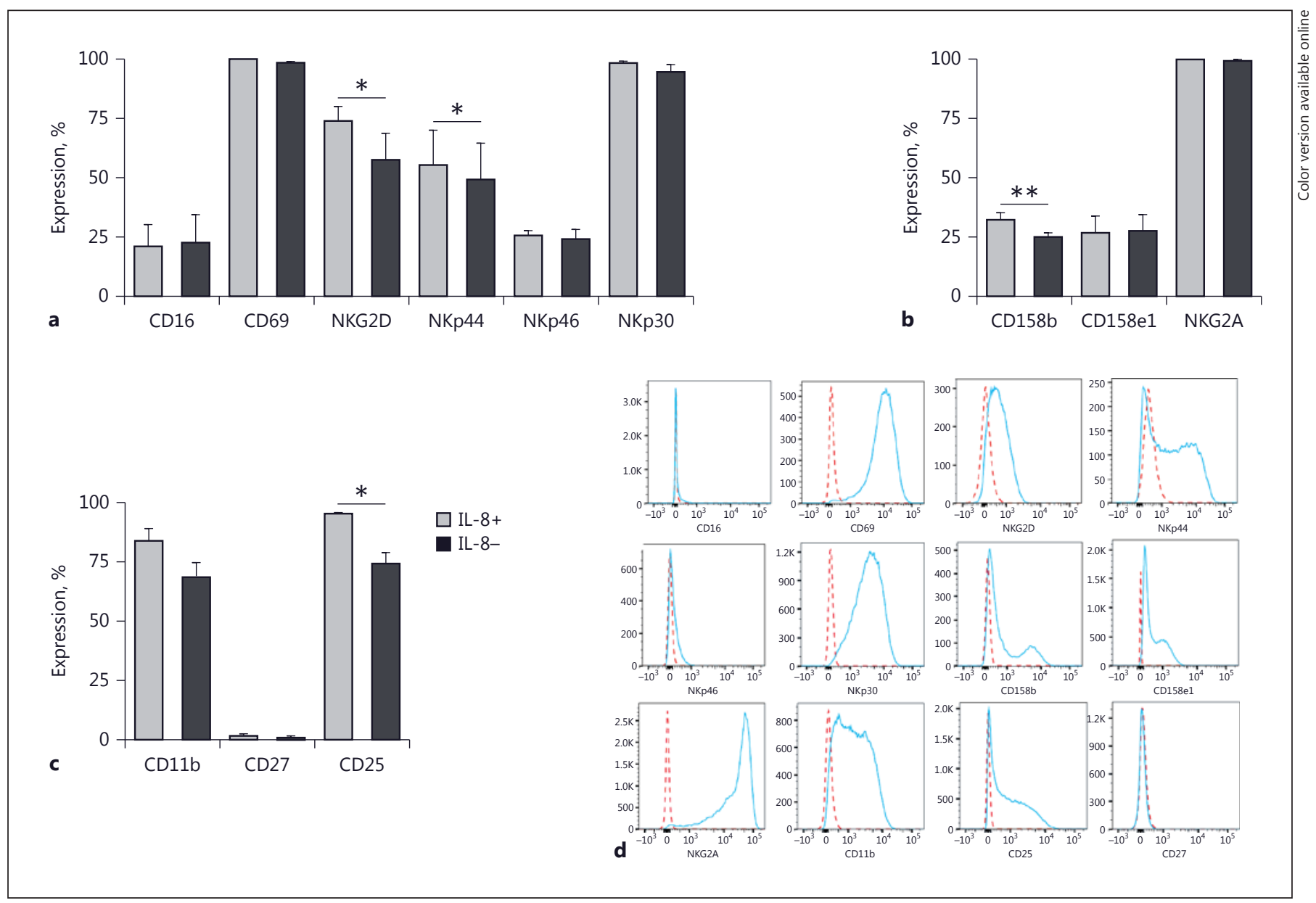

Fig. 6. Interleukin (IL)-8+ natural killer (NK) cells are phenotypically similar to IL-8- NK cells. Expanded NK cells were stained for phenotypic markers following IL-18 and IL-12 (IL-18+IL-12) stimulation and assessed via flow cytometry. The proportions of activation markers (a), inhibitory markers (b), and maturation markers (c) were compared between the IL-8+ and IL-8- populations. Results were analyzed using an unpaired $t$ test. ${ }^{* *} p<0.01$, $* p<0.05(n=3-5)$. d Representative histograms of the isotype control (dashed) compared to expression on NK cells (solid) are shown for each marker. K, thousand. marker compared to the isotype control are shown in Figure $6 \mathrm{~d}$. IL-8+ NK cells expressed marginally greater levels of the activating receptors NKG2D and NKp44, the inhibitory receptor CD158b, and the high-affinity IL-2 receptor CD25. However, overall both the IL-8+ and the IL-8- NK cells populations were phenotypically similar with respect to the expression of all 3 different groups of markers.

\section{IL-8 and IFN- $\gamma$ Follow a Similar Pattern of}

Production Following IL-18+IL-12 Stimulation

whereas TNF- $\alpha$ Levels Increase prior to IL-8 Levels

Having established that IL-18+IL-12 induces IL-8 production by NK cells in multiple contexts, we then sought to determine whether other mediators may be involved in inducing IL- 8 production. Both IFN- $\gamma$ and TNF- $\alpha$ have been shown to affect IL- 8 production in different immune cell types $[29,30]$. Given that IFN- $\gamma$ and TNF- $\alpha$ are also upregulated by NK cells following IL$18+$ IL-12 stimulation, we assessed whether IFN- $\gamma$ or TNF- $\alpha$ had an intermediate role in inducing NK cell IL-8 production. First, we characterized the temporal pattern of IL-8 production and compared this to the pattern of IFN- $\gamma$ and TNF- $\alpha$ production. Expanded NK cells were stimulated for $24 \mathrm{~h}$ and then washed of cytokines. Supernatants were collected at multiple time points following the beginning of stimulation and used for IL-8 (Fig. 7a), IFN- $\gamma$ (Fig. 7b), and TNF- $\alpha$ (Fig. 7c) ELISAs to quantify 


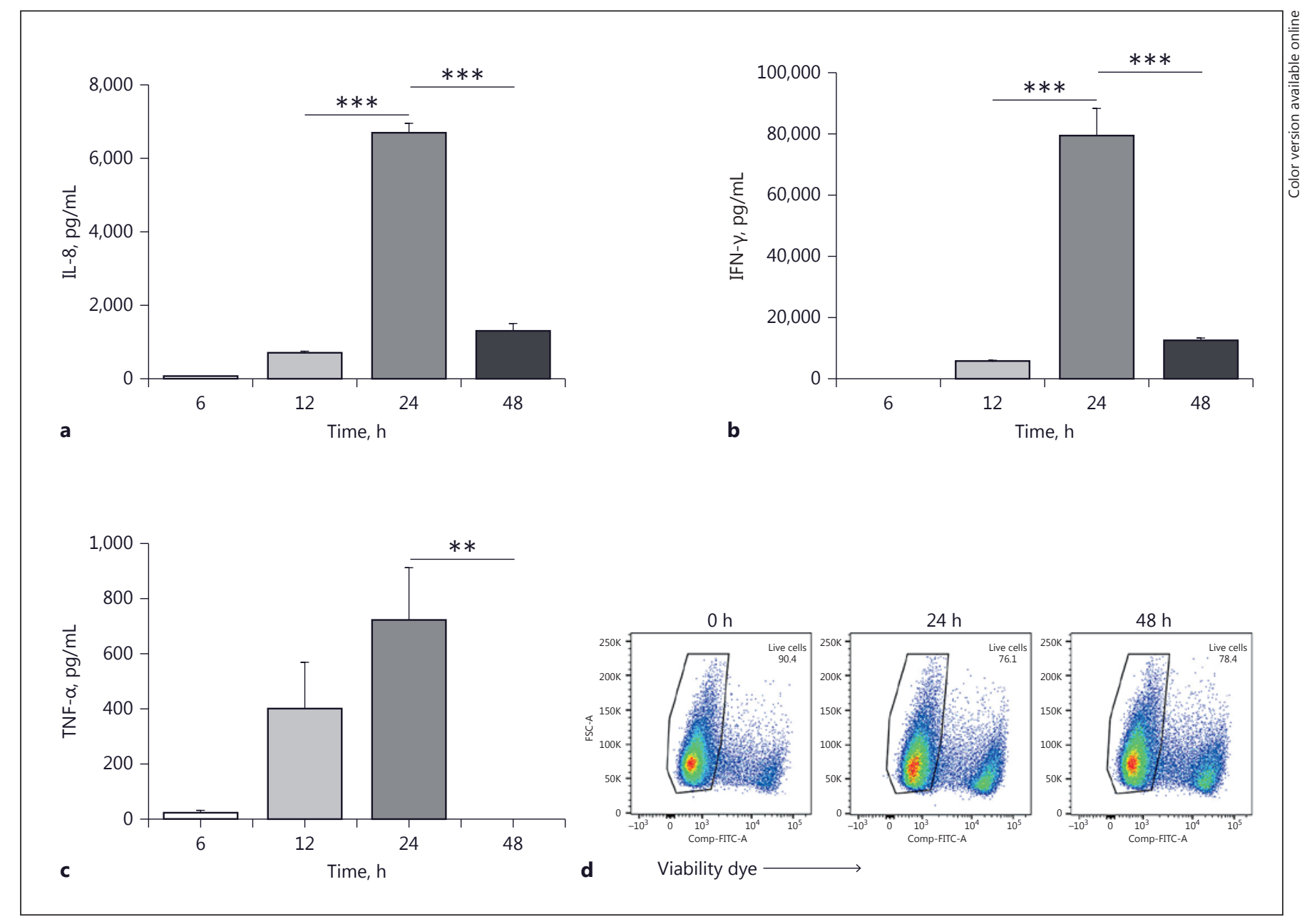

Fig. 7. Interleukin (IL)- 8 and interferon (IFN)- $\gamma$ follow a similar pattern of production whereas tumor necrosis factor (TNF)- $\alpha$ levels increase prior to IL-8 levels. Expanded natural killer (NK) cells were stimulated for $24 \mathrm{~h}$ and then washed of cytokines. Supernatants were collected at indicated time points and used to quantify
IL-8 $(n=3)(\mathbf{a})$, IFN- $\gamma(n=3)(\mathbf{b})$, and TNF- $\alpha(n=3)$ levels (c) via ELISA. d NK cell viability was assessed prior to stimulation $(0 \mathrm{~h})$, following $24 \mathrm{~h}$ of stimulation ( $24 \mathrm{~h}$ ), and again $24 \mathrm{~h}$ after washing $(48 \mathrm{~h})$. Results were analyzed via one-way ANOVA. ${ }^{* * *} p<0.001$, ** $p<0.01$. K, thousand. respective cytokine levels. Relative levels of IL- 8 and IFN- $\gamma$ followed a similar pattern of production: the majority of IL-8 and IFN- $\gamma$ was produced between 12 and $24 \mathrm{~h}$ of stimulation and both IL- 8 and IFN- $\gamma$ levels diminished following the removal of cytokines at $24 \mathrm{~h}$, although the viability remained comparable (Fig. $7 \mathrm{~d}$ ). Conversely, there was a trend for TNF- $\alpha$ levels increasing relative to peak levels prior to IL- 8 and IFN- $\gamma$, with over half of the TNF- $\alpha$ produced between 6 and $12 \mathrm{~h}$. The delay in IL-8 production compared to TNF- $\alpha$ indicates that the mechanism of IL- 8 production may differ from that of TNF- $\alpha$ and that other mediators may be involved in inducing IL-8.

\section{TNF- $\alpha$, but not IFN- $\gamma$, Partially Regulates IL-8}

\section{Production}

In order to assess whether IFN- $\gamma$ or TNF- $\alpha$ affects NK cell IL-8 production, expanded NK cells were stimulated with IL-18+IL-12 alone or with the addition of a neutralizing anti-IFN- $\gamma$, anti-TNF- $\alpha$, or isotype control antibody, all at $10 \mu \mathrm{g} / \mathrm{mL}$ (Fig. 8a). While neutralization of IFN- $\gamma$ had no effect on IL-8 production, remarkably, neutralization of TNF- $\alpha$ significantly reduced IL- 8 production by approximately $50 \%$ as compared to NK cells stimulated with IL-18+IL-12. A similar inhibition of IL-8 production was observed using concentrations of the anti-TNF- $\alpha$ antibody ranging from 5 to $100 \mu \mathrm{g} / \mathrm{mL}$, whereas inhibition 
Fig. 8. The mechanism of interleukin (IL)18 and IL-12 (IL-18+IL-12)-induced cytokine production involves tumor necrosis factor (TNF)- $\alpha$ and IL- 8 as intermediates. Expanded natural killer (NK) cells were stimulated with IL-18+IL-12 alone or with the addition of $10 \mu \mathrm{g} / \mathrm{mL}$ of anti-IFN- $\gamma$, anti-TNF- $\alpha$, or isotype control (ISO) antibody (a) or 10 or $1 \mu \mathrm{g} / \mathrm{mL}$ of etanercept (ETN) (b). IL-8 levels were quantified via ELISA. c Expanded NK cells were stimulated (Stim) with indicated cytokine combinations or media for $24 \mathrm{~h}(0-24 \mathrm{~h})$. At 24 $h$, the wells were washed and recombinant TNF- $\alpha(r T N F-\alpha)$ was added to the indicated wells for an additional $24 \mathrm{~h}(24-48 \mathrm{~h})$. IL-8 levels quantified via ELISA. d, e Expanded NK cells were stimulated with IL$18+\mathrm{IL}-12$ with the addition of $10 \mu \mathrm{g} / \mathrm{mL}$ of an IL-8 neutralizing antibody or ISO. Supernatants were collected following $24 \mathrm{~h}$ of stimulation and used to quantify IFN- $\gamma$ (d) and TNF- $\alpha$ levels (e) via ELISA. Results were analyzed via one-way ANOVA. *** $p<0.001,{ }^{* *} p<0.01,{ }^{*} p<0.05$ ( $n=3$ for all of the graphs).

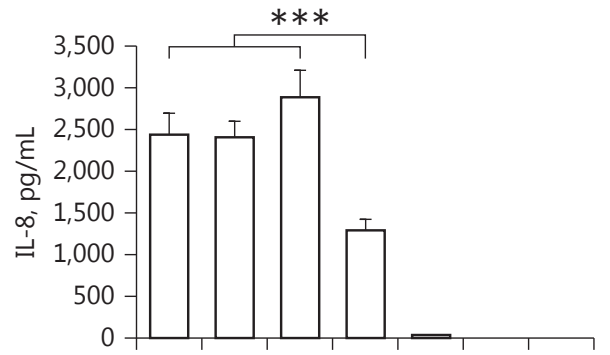

a
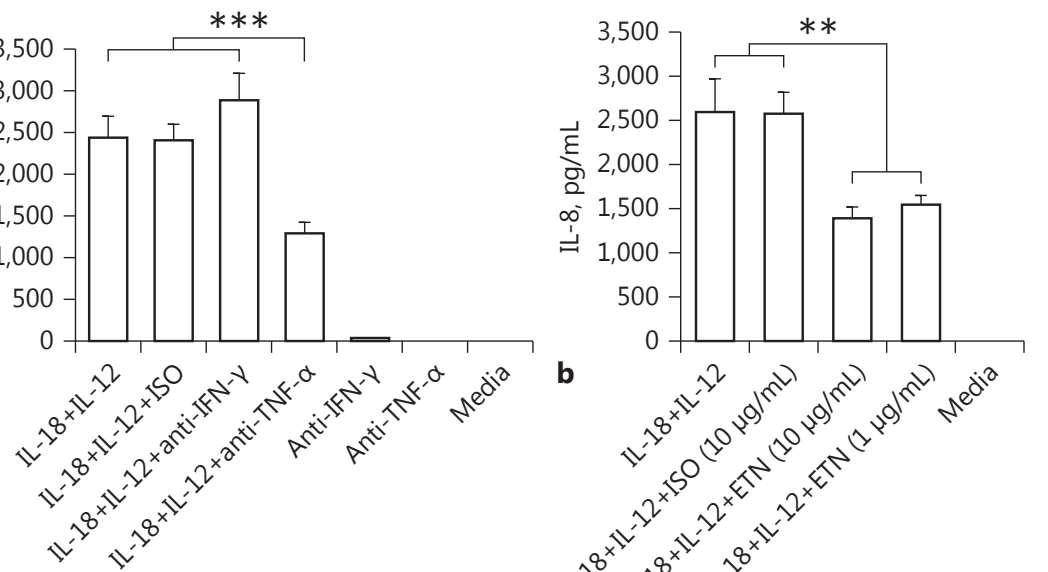

b
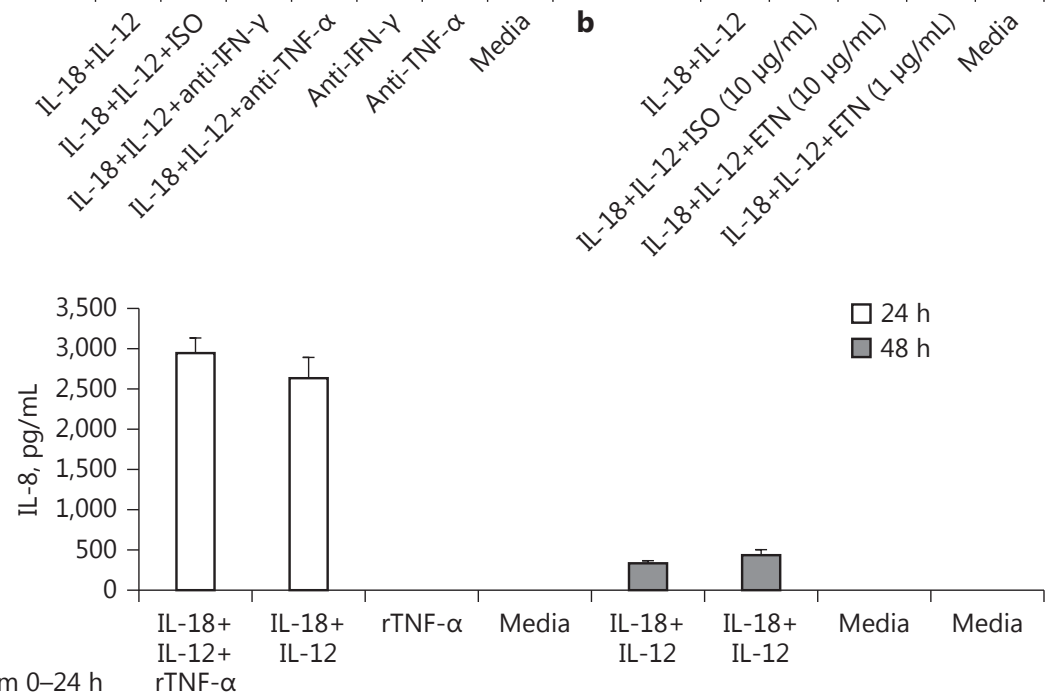

Stim 24-48 h

rTNF- $\alpha$ Media rTNF- $\alpha$ Media

c
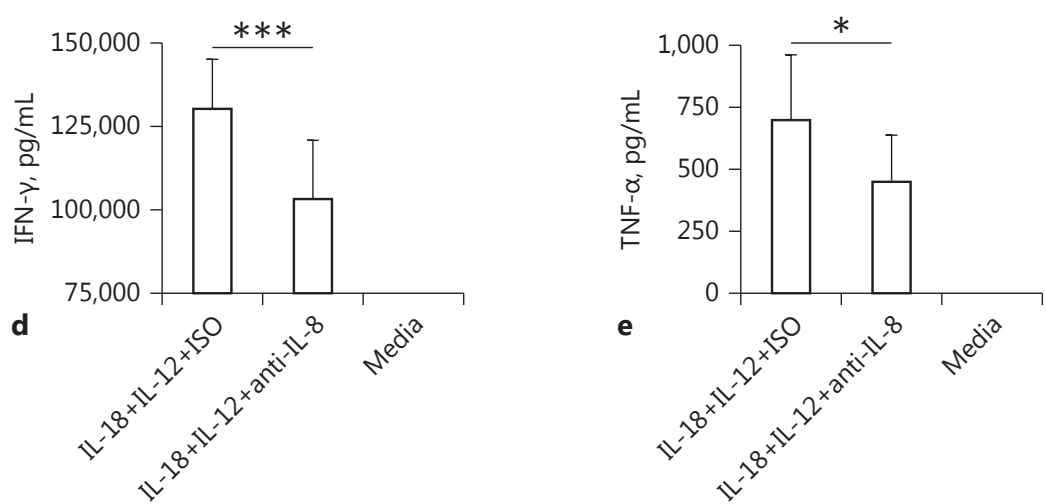

of IFN- $\gamma$ had no effect on IL-8 production with even 100 $\mu \mathrm{g} / \mathrm{mL}$ of neutralizing antibody (data not shown). In addition, TNF- $\alpha$ receptor blockade using etanercept at both 1 and $10 \mu \mathrm{g} / \mathrm{mL}$ inhibited IL-8 production similarly to the effects of TNF- $a$ cytokine neutralization (Fig. 8b). Taken together, these results demonstrate that TNF- $\alpha$ induced

IL-18+IL-12 Induces IL-8 Production by NK Cells by IL-18+IL-12 stimulation is produced by NK cells prior to IL-8 and it plays an intermediate role by acting in an autocrine manner to amplify the synergistic effect of IL$18+$ IL-12 on NK cell IL-8 production.

To further characterize the synergy of TNF- $\alpha$ with IL$18+\mathrm{IL}-12$, we assessed the effects of adding additional re-

J Innate Immun 2017;9:511-525 
combinant TNF- $\alpha(r-T N F-\alpha)$ at different time points of stimulation on IL-8 production (Fig. 8c). rTNF- $\alpha$ was added with IL-18+IL-12 at the beginning of stimulation to distinguish whether additional TNF- $\alpha$ could further enhance IL-8 production. rTNF- $\alpha$ was added following washing after $24 \mathrm{~h}$ of IL-18+IL-12 stimulation to distinguish whether IL-18+IL-12 could prime NK cells to respond to TNF- $\alpha$ in a temporal manner or whether the presence of TNF- $\alpha$ is required simultaneously with IL$18+\mathrm{IL}-12$ for the enhancement of IL- 8 production. The addition of rTNF- $\alpha$ with IL-18+IL-12 at the beginning of stimulation did not further enhance IL- 8 production, demonstrating that while TNF- $\alpha$ is required for optimal IL-8 production the signaling involved in enhancing IL-8 production is saturated at the endogenous concentrations of TNF- $\alpha$ produced by NK cells. Furthermore, the addition of rTNF- $\alpha$ at $24 \mathrm{~h}$ following IL-18+IL-12 stimulation did not induce IL-8 production, demonstrating either that the presence of IL-18+IL-12 is required for the synergistic effect of TNF- $\alpha$ or that TNF- $\alpha$ signaling must occur early during IL-18+IL-12 stimulation.

\section{IL-8 Plays an Intermediate Role in Regulating NK Cell} IFN- $\gamma$ and TNF- $\alpha$ Production

To determine whether IL-8 in turn has the capacity to affect the NK cell response to stimulation, we added an IL-8-neutralizing antibody during IL-18+IL-12 stimulation and assessed the effects of IL- 8 neutralization on IFN- $\gamma$ and TNF- $\alpha$ production. Interestingly, IL- 8 inhibition significantly reduced both IFN- $\gamma$ (Fig. 8d) and TNF- $\alpha$ (Fig. 8e) production, indicating that the IL- 8 produced by NK cells acts in an autocrine or paracrine manner to further enhance the cytokine response of IL-18+IL-12-stimulated NK cells.

\section{Discussion}

It has been well documented that stimulation with the combination of IL-18+IL-12 potently activates NK cells, inducing high levels of IFN- $\gamma$ production. This activation is an important immune response to infections and it is currently being explored for cancer immunotherapies. However, to date, studies have primarily characterized this response in terms of IFN- $\gamma$ production, with little focus on other cytokines produced. Given the importance of this response, it was pertinent to identify whether other cytokines are highly upregulated by NK cells in response to IL-18+IL-12. In the present study, we reveal that IL-18+IL-12 stimulation potently induces IL-8 pro- duction by NK cells, characterize this response in multiple contexts, and identify critical roles for TNF- $\alpha$ and IL- 8 as intermediates that regulate IL-18+IL-12-induced NK cell cytokine production.

Microarray analysis of IL-18+IL-12-stimulated expanded NK cells revealed that IL-8 was among the top most upregulated mRNA. This was an unexpected response by peripheral blood NK cells, as high levels of IL- 8 production are more classically associated with decidual NK cells, which are immunoregulatory, angiogenic, and functionally very distinct from cytotoxic peripheral blood NK cells [25]. Given the angiogenic and tumor-promoting functions of IL-8, along with its critical roles in the response to infections, it was important to determine whether these elevated levels of IL-8 mRNA translated to protein production and, if so, whether this was uniquely a phenomenon of expanded NK cells, or whether this occurred by NK cells in multiple contexts. Indeed, IL$18+$ IL-12 synergistically induced high levels of IL-8 production by both expanded and freshly isolated NK cells as well as by NK cells in the context of PBMC. While levels of IL-8 varied among NK cells in different contexts, assessment of MFI confirmed that freshly isolated NK cells produced more IL- 8 on a per cell basis than ex vivo expanded NK cells. Interestingly, we found that IL-8 production was not limited to the CD56 $6^{\text {bright }} \mathrm{NK}$ cell population, as both $\mathrm{CD} 56^{\text {bright }}$ and $\mathrm{CD} 56^{\mathrm{dim}}$ peripheral blood NK cell subsets expressed IL-8 following IL-18+IL-12 stimulation. The production of IL- 8 by NK cells in isolation indicates that IL-18 and IL-12 act directly on NK cells to induce this response. IL- 8 production by NK cells in the context of PBMC demonstrates that this response also occurs in the presence of other immune cells, where additional signals including other cytokines and cell-cell interactions are present, which more closely resembles an in vivo environment.

We report that IL-15 and IL-2 additionally enhance IL- 8 production by stimulated NK cells, which suggests that the IL-8 response may be enhanced in an in vivo context in which these cytokines are present, and in immunotherapies in which NK cells are preactivated with IL18/IL-15/IL-12. The enhancement of IL-8 production by these common $\gamma$-chain cytokines is likely attributable to the previous finding that common $\gamma$-chain cytokines are capable of synergizing with IL-18 to activate NK cells [27]. Our findings indicate a potential role for the K562mb-IL-21 cells in culture to prime expanded NK cells for IL-8 production since they express membrane-bound IL21 , another common $\gamma$-chain cytokine. While only modest phenotypic distinctions were observed between the
522

J Innate Immun 2017;9:511-525

DOI: $10.1159 / 000477172$
Poznanski/Lee/Nham/Lusty/Larché/Lee/ Ashkar 
IL-8+ and IL-8- NK cell populations using common phenotypic markers, our finding that the IL-8+ population had a greater expression of the IL-2 receptor CD25 than IL-8- cells suggests that other factors such as the differential expression of cytokine receptors may distinguish these populations.

Although IL- 8 production by NK cells is classically associated with $\mathrm{CD} 56^{\text {bright }}$ decidual NK cells, there have been some reports of IL-8 production by peripheral blood NK cells following certain methods of stimulation. Mainiero et al. [31] demonstrated that $\beta_{1}$-integrin ligation on human NK cells induced IL-8 production through p38 MAPK signaling. In addition, IL-8 has been detected following combined stimulation of NK cells with CD16 monoclonal antibodies and various cytokines [32]. However, none of these methods of stimulation yield the striking levels of IL-8 produced particularly by freshly isolated NK cells following IL-18+IL-12 stimulation. Interestingly, stimulation of NK cells with platelet factor 4 has been shown to also induce remarkable levels of IL-8 production in peripheral blood NK cells via a mechanism dependent on the PI-3K pathway [33]. Our discovery of IL-8 production by IL-18+IL-12-activated NK cells in complement with these studies indicates that IL-8 production may be a response more characteristic of activated peripheral blood NK cells than previously appreciated.

We identified TNF- $\alpha$, produced by NK cells in response to IL-18+IL-12, as an intermediate that enhances NK cell IL-8 production in an autocrine manner. Tufa et al. [34] demonstrated that IL-12 stimulation induces the upregulation of the TNF- $\alpha$ receptor TNFR2 on the surface of NK cells, suggesting the possibility for NK cells stimulated with IL-18+IL-12 to have an enhanced responsiveness to TNF- $\alpha$. While an enhanced responsiveness to TNF- $\alpha$ may contribute to the intermediary effect of TNF- $\alpha$ on IL- 8 production, we found that the added synergistic effect of TNF- $\alpha$ required the simultaneous presence of TNF- $\alpha$ with IL-18+IL-12. Previous studies have implicated TNF- $\alpha$ in either IL-12- or IL-18-induced IL-8 production. TNF- $\alpha$ has been shown to have an intermediate role in IL-12-induced IL-8 production by polymorphonuclear neutrophils [35]. Furthermore, IL-18-induced IL- 8 production by PBMC and NK cells has been shown to require TNF- $\alpha$ [30]. However, to our knowledge, this is the first study to implicate TNF- $\alpha$ in the mechanism for the synergistic effect of IL-18+IL-12 on NK cells. In addition, we demonstrate that the IL- 8 produced as a result of IL-18+IL-12 stimulation further activates NK cell IFN- $\gamma$ and TNF- $\alpha$ production. Overall, these results further elucidate the mechanism of IL-

IL-18+IL-12 Induces IL-8 Production by NK Cells
18+IL-12 synergy by demonstrating that while IL$18+$ IL-12 initiates NK cell stimulation and cytokine production, other intermediates produced as a result of stimulation are required to propagate maximal NK cell activation in response to IL-18+IL-12. Given that IL$18+$ IL-12 synergy has multiple effects on NK cells, including the induction of memory-like NK cells, enhanced cytotoxicity, and IFN- $\gamma$ production, future studies would warrant investigating the contribution of intermediates to these other synergistic effects.

Multiple strategies exploiting the synergistic effect of IL-18+IL-12 are being developed as cancer immunotherapies, with IL-18+IL-15+IL-12 preactivated NK cells currently in clinical trials [18]. IL-8 produced as a result of IL-18+IL-12 stimulation may have profound implications for cancer immunotherapies. There is a wealth of evidence implicating IL-8 in tumor progression [24], suggesting a potential tumor-promoting role for the IL- 8 released by NK cells in response to IL-18+IL-12. However, some studies have revealed evidence for antitumor activity of IL-8 in certain contexts. One such study was a clinical trial in which Her2+ cancer patients were treated with the combination of IL-12 and a Her2 monoclonal antibody that stimulates NK cells via CD16 [36]. In their preclinical work, they found that this combination treatment induced modest amounts of IL- 8 production by NK cells, which stimulated T-cell chemotaxis [32]. Interestingly, in the clinical trial, it was found that peak levels of IL-8 in the serum were elevated in patients with favorable clinical outcomes as compared to patients with progressive disease [36]. Another study by Laprevotte et al. [37] demonstrated a critical role for IL-8 in the NK cell-mediated depletion of leukemia cells following rituximab treatment for chronic lymphocytic leukemia. These conflicting implications for IL-8 in cancer regulation suggest that the effects of IL- 8 may depend on the type of environment in which it is being released. In the immunosuppressive environment of the tumor, IL- 8 recruits neutrophils that release proangiogenic factors and other immune cells that are likely to be converted to a regulatory, tumor-promoting phenotype [38]; however, in a proinflammatory environment, such as that in which IL-18+IL-12-activated NK cells are also producing high levels of IFN- $\gamma$, IL- 8 may play a role in recruiting and activating immune cells that acquire an antitumor phenotype as a result of proinflammatory signals. While our results demonstrate that IL-8 produced by NK cells further potentiates NK cell proinflammatory functions such as IFN- $\gamma$ and TNF- $\alpha$ production in vitro, it is imperative that future studies delineate the effects of IL- 8 produced by IL-18+IL-12-activated NK

J Innate Immun 2017;9:511-525

DOI: $10.1159 / 000477172$ 
cells on immune cells in the context of the tumor microenvironment, wherein the tumor-promoting functions of IL- 8 could weigh against the immune activating functions.

In addition to cancer immunotherapies, IL-8 production by NK cells in response to IL-18+IL-12 stimulation may also have implications for the immune response to infections, particularly as IL-8 production was found to occur in NK cells in PBMC. NK cells play a key role in the early initiation of the immune response and coordination of the adaptive response. IL-18 and IL-12 are released early in response to infections by APC, inducing NK cell activation [5-7]. IL-8 both recruits and activates numerous innate and adaptive immune cell types, including neutrophils, monocytes, NK cells, and T cells and it has been shown to be critical for host defense in response to numerous infections [19-23]. Our results that NK cells contribute significantly to the IL- 8 produced in PBMC following IL-18+IL-12 stimulation indicate a further mechanism through which NK cells may exert their roles as initiators and coordinators of the immune response to infection via recruitment and activation of other immune cells.

Our present discovery that IL-18+IL-12 stimulation synergistically induces IL- 8 production by NK cells in a mechanism involving TNF- $\alpha$ has implications for both the immune response to infections and cancer immunotherapies utilizing IL-18 and IL-12. Overall, this study furthers our understanding of NK cell function and IL18+IL-12 synergy by revealing and characterizing an unprecedented response by IL-18+IL-12-activated peripheral blood NK cells to produce high levels of IL- 8 and identifying the role of intermediates in the mechanism of IL-18+IL-12 synergy.

\section{Acknowledgements}

This work was supported by a grant from the Canadian Breast Cancer Foundation, Ontario Chapter. The authors would like to thank all blood donors, and Jann Ang, Natasha Kazhdan, and Dessi Loukov, for their help with blood collection.

\section{References}

1 Geller MA, Miller JS: Use of allogeneic NK cells for cancer immunotherapy. Immunotherapy 2011;3:1445-1459.

2 Scully E, Alter G: NK cells in HIV disease. Curr HIV/AIDS Rep 2016;13:85-94.

3 Bodduluru LN, Kasala ER, Madhana RM, Sriram CS: Natural killer cells: the journey from puzzles in biology to treatment of cancer. Cancer Lett 2015;357:454-467.

4 Vivier E, Tomasello E, Baratin T, Walzer T, Ugolini S: Functions of natural killer cells. Nat Immunol 2008;9:503-510

5 Goldszmid RS, Caspar R, Rivollier A, White S, Dzutsey A, Hieny S: NK cell-derived interferon-gamma orchestrates cellular dynamics and the differentiation of monocytes into dendritic cells at the site of infection. Immunity 2012;36:1047-1059.

6 Bellora F, Castricioni R, Doni A, Cantoni C, Moretta L, Mantovani A, Moretta A, Bottino C: M-CSF induces the expression of a membrane-bound form of IL-18 in a subset of human monocytes differentiating in vitro toward macrophages. Eur J Immunol 2012;42: 1618-1626.

7 Borg C, Jalil A, Laderach D, Maruyama K, Wakasugi H, Charrier S, Ryffel B, Cambi A, Figdor C, Vainchenker W, Galy A, Caignard A, Zitvogel L: NK cell activation by dendritic cells (DCs) requires the formation of a synapse leading to IL-12 polarization in DCs. Blood 2004:104:3267-3275.
8 Semino C, Angelini G, Poggi A, Rubartelli A: $\mathrm{NK} / \mathrm{iDC}$ interaction results in IL-18 secretion by DCs at the synaptic cleft followed by NK cell activation and release of the DC maturation factor HMGB1. Blood 2005; 106:609616

9 Takeda K, Tsutsui H, Yoshimoto T, Adachi O, Yoshida N, Kishimoto T, Okamura H, Nakanishi K, Akira S: Defective NK cell activity and Th1 response in IL-18-deficient mice. Immunity 1998;8:383-390.

10 Chaix J, Tessmer MS, Hoebe K, Fuséri N, Ryffel B, Dalod M, Alexopoulou L, Beutler B, Brossay L, Vivier E, Walzer T: Cutting edge: priming of NK cells by IL-18. J Immunol 2008;181:1627-1631.

11 Freeman BE, Raué HP, Hill AB, Slifka MK: Cytokine-mediated activation of NK cells during viral infection. J Virol 2015;89:79227931.

12 Martinovic KM, Babovic N, Dzodic R, Jurisic V, Matkovic S, Gordana K: Favorable in vitro effects of combined IL-12 and IL-18 treatment on NK cell cytotoxicity and CD25 receptor expression in metastatic melanoma patients. J Transl Med 2015;13:120.

13 Cooper MA, Elliott JM, Keyel PA, Yang L, Carrero JA, Yokoyama WM: Cytokine-induced memory-like natural killer cells. Proc Natl Acad Sci USA 2009;106:1915-1919.
14 Fehniger TA, Shah MH, Turner MJ, VanDeusen JB, Whitman SP, Cooper MA, Suzuki K, Wechser M, Goodsaid F, Caligiuri MA: Differential cytokine and chemokine gene expression by human NK cells following activation with IL-18 or IL-15 in combination with IL-12: implications for the innate immune response. J Immunol 1999;162:4511-4520.

15 Ardolino M, Azimi CS, Ianello A, Trevino TN, Horan L, Zhang L, Deng W, Ring AM, Fischer S, Garcia KC, Raulet DH: Cytokine therapy reverses NK cell anergy in MHC-deficient tumors. J Clin Invest 2014;124:47814794.

16 Shiratori I, Suzuki Y, Oshiumi H, Begum NA, Ebihara T, Matsumoto M, Hazeki K, Kodama K, Kashiwazi Y, Seya T: Recombinant interleukin-12 and interleukin-18 antitumor therapy in a guinea-pig hepatoma cell implant model. Cancer Sci 2007;98:1936-1942.

17 Ni J, Miller M, Stojanovic A, Garbi N, Cerwenka A: Sustained effector function of IL12/15/18-preactivated NK cells against established tumors. J Exp Med 2012;209:23512365.

18 Romee R, Rosario M, Berrien-Elliott MM, Wagner JA, Jewell BA, Schappe T, Leong JW, Abdel-Latif S, Scheider SE, Willey S, Neal CC, Yu L, Oh ST, Lee YS, Mulder A, Claas F, Cooper MA, Fehniger TA: Cytokine-induced memory-like natural killer cells exhibit enhanced responses against myeloid leukemia. Sci Transl Med 2016;8:357ra123.

Poznanski/Lee/Nham/Lusty/Larché/Lee/ Ashkar
Innate Immun 2017;9:511-525

DOI: $10.1159 / 000477172$ 
19 Van Damme J, Van Beeumen J, Opdenakker G, Billiau A: A novel, NH2-terminal sequence-characterized human monokine possessing neutrophil chemotactic, skin-reactive, and granulocytosis-promoting activity. J Exp Med 1988;167:1364-1376.

20 Larsen CG, Anderson AO, Appella E, Oppenheim JJ, Matsushima K: The neutrophil-activating protein (NAP-1) is also chemotactic for T lymphocytes. Science 1989;243:14641466.

21 Vujanovic L, Ill WB, Thorne SH, Vujanovic NL, Butterfield LH: Adenovirus-engineered human dendritic cells induce natural killer cell chemotaxis via CXCL8/IL-8 and CXCL10/ IP-10. Oncoimmunology 2012;1:448-457.

22 Del Rio L, Bennouna S, Salinas J, Denkers EY: CXCR2 deficiency confers impaired neutrophil recruitment and increased susceptibility during Toxoplasma gondii infection. J Immunol 2001;167:6503-6509.

23 Herbold W, Maus R, Hahn I, Ding N, Srivastava M, Christman JW, Mack M, Reutershan J, Briles DE, Paton JC, Winter C, Welte T, Maus UA: Importance of CXC chemokine receptor 2 in alveolar neutrophil and exudate macrophage recruitment in response to pneumococcal lung infection. Infect Immun 2010; 78:2620-2630.

24 Campbell LM, Maxwell PJ, Waugh DJJ: Rationale and means to target pro-inflammatory interleukin-8 (CXCL8) signaling in cancer. Pharmaceuticals 2013;6:929-959.

25 Hanna J, Goldman-Wohl D, Hamani Y, Avraham I, Greenfield C, Natanson-Yaron S, Prus D, Cohen-Daniel L, Arnon TI, Manaster I, Gazit R, Yutkin V, Benharroch D, Porgador A, Keshet E, Yagel S, Mandelboim O: Decidual NK cells regulate key developmental processes at the human fetal-maternal interface. Nat Med 2006;12:1065-1074.
26 Denman CJ, Senyukov VV, Somanchi SS, Phatarpekar PV, Kopp LM, Johnson JL, Singh H, Hurton L, Maiti SN, Huls MH, Champlin RE, Cooper LJ, Lee DA: Membrane-bound IL-21 promotes sustained ex vivo proliferation of human natural killer cells. PLoS One 2012;7:e30264.

27 Nielsen CM, Wolf AS, Goodier MR, Riley EM: Synergy between common $\gamma$ chain family cytokines and IL- 18 potentiates innate and adaptive pathways of $\mathrm{NK}$ cell activation. Front Immunol 2016;7:101.

28 Leong JW, Chase JM, Romee R, Schneider SE, Sullivan RP, Cooper MA, Fehniger TA: Preactivation with IL-12, IL-15, and IL-18 induces CD25 and a functional high-affinity IL-2 receptor on human cytokine-induced memory-like natural killer cells. Biol Blood Marrow Transplant 2014;20:463-473.

29 Sorimachi K, Akimoto K, Yamazaki S: Modulation of interleukin- 8 and nitric oxide synthase mRNA levels by interferon-gamma in macrophages stimulated with lignin derivatives and lipopolysaccharides. Cancer Detect Prev 2003;27:1-4.

30 Puren AJ, Fantuzzi G, Gu Y, Su MS, Dinarello CA: Interleukin-18 (IFNgamma-inducing factor) induces IL-8 and IL-1b via TNFalpha production from non-CD14+ human blood mononuclear cells. J Clin Invest 1998;101: 711-721.

31 Mainiero F, Soriani A, Strippoli R, Jacobelli J, Gismondi A, Piccoli M, Frati L, Santoni A: RAC1/P38 MAPK signaling pathway controls beta1 integrin-induced interleukin-8 production in human natural killer cells. Immunity 2000;12:7-16.
32 Roda JM, Parihar R, Magro C, Nuovo GJ, Tridandapani S, Carson WE 3rd: Natural killer cells produce $\mathrm{T}$ cell-recruiting chemokines in response to antibody-coated tumor cells. Cancer Res 2006;66:517-526.

33 Marti F, Bertran E, Llucià M, Villén E, Peiró M, Garcia J, Rueda F: Platelet factor 4 induces human natural killer cells to synthesize and release interleukin-8. J Leukoc Biol 2002;72: 590-597.

34 Tufa DM, Chatterjee D, Low HZ, Schmidt RE, Jacobs R: TNFR2 and IL-12 coactivation enables slanDCs to support NK-cell function via membrane-bound TNF- $\alpha$. Eur J Immunol 2014;44:3713-3728.

35 Ethuin F, Delarche C, Benslama S, GougerotPocidalo MA, Jacob L, Chollet-Martin S: Interleukin-12 increases interleukin 8 production and release by human polymorphonuclear neutrophils. J Leukoc Biol 2001;70: 439-446.

36 Bekaii-Saab TS, Roda JM, Guenterberg KD, Ramaswamy B, Young DC, Ferketich AK, Lamb TA, Grever MR, Shapiro CL, Carson WE 3rd: A phase I trial of paclitaxel and trastuzumab in combination with interleukin-12 in patients with HER2/neu-expressing malignancies. Mol Cancer Ther 2009;8:29832991.

37 Laprevotte E, Ysebaert L, Klein C, Valleron W, Blanc A, Gross E, Laurent G, Fournié JJ, Quillet-Mary A: Endogenous IL-8 acts as a CD16 co-activator for natural killer-mediated anti-CD20 B cell depletion in chronic lymphocytic leukemia. Leuk Res 2013;37:440446.

38 Todorovic-Rakovic N, Milovanovic J: Interleukin-8 in breast cancer progression. J Interferon Cytokine Res 2013;33:563-570. 